\title{
CONTROLS TO ELIMINATE BROKEN RAILS IN SERVICE
}

\author{
John Tunna \\ Federal Railroad Administration \\ Washington, DC, USA \\ David Jeong \\ Volpe National Transportation Systems Center \\ Cambridge, MA, USA
}

\author{
Jeff Gordon \\ Federal Railroad Administration \\ Cambridge, MA, USA \\ Carlo Patrick \\ Federal Railroad Administration \\ Washington, DC, USA
}

\begin{abstract}
Broken rails in freight and passenger revenue service occur due to single, or combinations of, faults or failures of various kinds. These may occur due to limitations inherent in the rail defect inspection process, track maintenance and renewal practices, and may also arise due to changes in operating conditions. The Government and the industry have developed regulations, standards and procedures to control these issues and reduce broken rail occurrences. This paper presents a broken rail fault tree as a way of visualizing the problem. It describes current controls and shows how they map onto the fault tree. Examples of recent broken rail derailments are used to illustrate the fault tree. Lessons learned are used to identify areas where further tightening of controls or the imposition of new controls may be required to further reduce the number of, and potentially eliminate, broken rails in service.
\end{abstract}

\section{INTRODUCTION}

Data from the Federal Railroad Administration's (FRA) accident and incident database for the five years from 2009 to 2013 shows that broken rails are historically the most significant cause of main line derailments. The average number of trains derailed each year was 75 and the average number of cars derailed each time was 12 . This gives a risk factor of $75 \mathrm{x}$ $12=900$ cars derailed per year. The next most significant cause is human error, which has a risk factor of 380 cars derailed per year. The recent history of broken rail derailments that have made the headlines continues to emphasize the seriousness of this failure mechanism.
Since a broken rail in revenue service can cause a freight or passenger train derailment it is clearly a safety hazard. Figure 1 presents a type of fault tree diagram for this hazard. There are countless ways such a fault tree can be drawn. This one was developed after internal discussions within FRA. Figure 1 is not intended to be the strict type of fault tree to which probabilities can be applied and calculations can be made. Instead, it is proposed as a way of illustrating the problem, and it forms the basis of the discussion in this paper.

Complementary to the fault tree is an event tree diagram. This illustrates the possible outcomes of a broken rail in service. Although not included in this paper, the event tree would show the likelihoods of the break being detected by the signaling track circuit or other means, or occurring under a train and causing a derailment. If a derailment did occur, the event tree would show the likelihoods of various consequences such as fatalities, injuries and property damage. Any further description of the broken rail event tree is outside the scope of this paper.

This paper discusses the role of Federal regulations and industry best practices in avoiding broken rails in revenue service. FRA's track safety regulations (1) have been developed in consultation with the industry and capture the latest minimum safety requirements.

Industry best practice is captured in the American Railroad Engineering and Maintenance of Way Association's (AREMA) standards (2), and in individual railroads' and suppliers' operating procedures. 


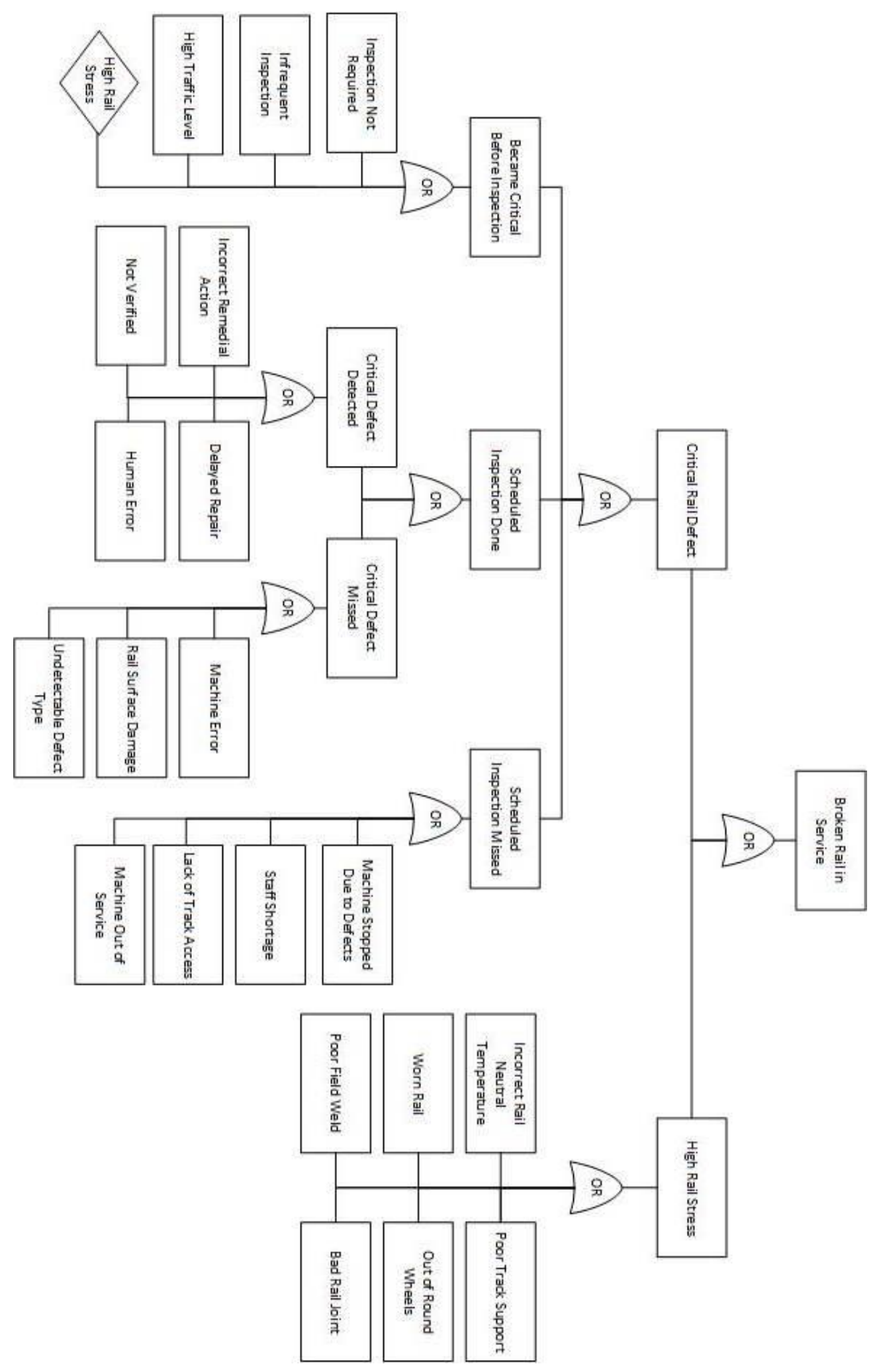

Figure 1. Broken Rail Fault Tree Diagram 


\section{FAULTS LEADING TO BROKEN RAILS IN SERVICE}

The following sections describe the faults in portions of the diagram in Figure 1, and the controls that are currently in place to prevent them.

A rail defect of sub-critical size should be able to withstand normal rail stresses without the rail breaking. Thus, for a broken rail to occur in revenue service either the defect has reached a critical size or the rail stresses are higher than normal. (Of course, it is possible that both conditions may be present.) In general:

- Rail inspection is performed to detect defects before they reach a critical size, and

- Track and equipment maintenance is performed to keep rail stresses at normal levels.

\section{HIGH RAIL STRESS}

Rail stress is a combination of thermal, residual and bending stresses, the magnitudes and distributions of which can be influenced by numerous factors including those discussed in the following sub-sections. Figure 1 shows that, in addition to causing non-critical rail defects to fail, high rail stress can also cause defects to grow to a critical size before the next inspection takes place.

\section{Rail Neutral Temperature}

Thermal rail stresses are controlled by adjusting the rail's neutral temperature. Too low a neutral temperature and the track is likely to buckle in the summer: too high a neutral temperature and the rail will go into a high state of tension in the winter, which increases the likelihood of a broken rail.

FRA's track safety standards require railroads to develop and follow Continuously Welded Rail management plans (1). These plans describe the railroads' various approaches to setting and maintaining rail neutral temperature. FRA reviews these plans and audits to ensure that the railroads comply with them, but it does not set rail neutral temperature limits in its regulations.

\section{Worn Rail}

In rail, wear is not a defect in the same sense as a crack, which is a stress raiser and intensifies the local state of stress, but it is a cause for rail removal. Excessive wear can reduce rail strength, increasing the risk of broken rails. Progressive vertical head-height loss may eventually lead to contact between the wheel flange and any joint bars, increasing the potential for wheel lift. Excessive gage-face side wear can result in gage widening, increasing the potential for wheel drop. Vehicle dynamics on curved rail with excessive vertical and side wear can create relatively high lateral loads, increasing the potential for wheel climb and the risk of broken wheel flanges.

Currently, there is no FRA regulation on allowable rail wear. Railroads follow their own rules for determining when rail needs to be replaced due to wear. Their rules differ in the amount of allowable head and side wear.

FRA has sponsored research to develop technical information on rail wear limits based on rail strength $(3,4)$. In this context, strength means resistance of the rail to fracture due to the presence of defects. This fracture mechanics approach assumes that cracks or defects exist - caused either from manufacturing processes or from fatigue - and that periodic rail tests are performed to detect them before they grow large enough to cause rail failure. Therefore, the allowable limits estimated from this approach depend on how often rail defect inspections are performed.

\section{Track Support}

Rail experiences bending stresses when wheels roll along it and as it deflects on the support provided by ties, ballast, and subgrade. The bending stresses in the rail due to normal variations in track vertical modulus do not typically generate high enough stresses to break the rail. However, poor support from ties and ballast that cause the rail to have to span a large distance or a short wavelength vertical deviation over a particularly stiff support structure (e.g., a bridge end) could generate the necessary stresses.

FRA's track safety standards require a minimum number of non-defective ties per 39 foot length for each Class of track to maintain appropriate vertical and lateral support of the track structure (1). In addition, high rail bending stresses caused by poor track support are limited by requiring ballast to be able to transmit and distribute loads to the sub-structure and to provide adequate drainage.

\section{Rail Joints}

Rail joints require special attention by railroad maintenance personnel and railroad inspectors. As far as possible, a rail joint should provide the same relative strength, stiffness, and uniformity as the rail itself to maintain proper load transfer.

Improper maintenance of a rail joint can result in excessive movement, high impact loads, and abnormal loading stress. This type of abnormal stressing of the joint can initiate rail defects within the confines of the rail end. It is not unusual to have a sudden rupture of a rail joint defect such as a bolt hole break or head and web separation occur when the joint is excessively stressed.

FRA regulations give maximum allowable tread and gage side rail end mismatches for different classes of track to control impact stresses (1). The regulations also require rail joints to be structurally sound and correctly dimensioned for the rails they join.

\section{Out of Round Wheels}

A wheel with a flat spot, or an out-of-round wheel, will impact the rail with every rotation. Flat spots occur when the brakes stick, which may be caused by a variety of reasons. The wheel slides instead of rolling, and a worn flat spot develops. 
Rails can break if the wheel impact load is sufficiently high. The wheel impact load to cause rail failure is greatly reduced if the rail contains a crack or a defect.

A current research question is whether wheel impacts accelerate the rate of growth of track defects throughout their life or if they are only responsible, in some cases, for final failure.

Wayside wheel impact load detectors are used to identify high-impact out-of-round wheels in revenue service. The Association of American Railroads (AAR), through its requirements for interchange service, sets limits for impact loads (5). Thresholds are set for advice, alerts, condemnation, and immediate action.

In April, 2015 the FRA issued a Safety Advisory recommending lower wheel impact load thresholds than currently used by the industry for High Hazard Flammable Trains (6).

\section{CRITICAL RAIL DEFECT}

Critical rail defects in revenue service can be there because: they became critical before the next scheduled inspection, the scheduled inspection did not take place, or something went wrong during the inspection.

\section{Inspection Interval}

If a defect becomes critical before the next inspection it may be because the inspection interval is too long or inspection is not required. Alternatively, it may be because the traffic or stress level is unusually high.

FRA requires that internal rail inspections on Class 4 and 5 track, or on Class 3 track with regularly-scheduled passenger trains or that is a hazardous materials route, not exceed a time interval of 370 days or a tonnage interval of 30 Million Gross Tons (MGT), whichever is shorter (1).

In the late 1990's, the railroads were generally testing more frequently than required by regulation. This led the FRA to implement a self-adaptive scheduling method that codified standard industry best practices (7). The self-adaptive scheduling method is performance-based. It allows the frequency of rail inspection cycles to vary according to: the total detected defect rate per test, the rate of service failures between tests, and the accumulated tonnage between tests. These are all factors that the railroad industry's rail quality managers generally consider when determining test schedules.

Current inspection interval regulations (1) require the railroads to maintain service failure rates of no more than:

- 0.1 service failure per year per mile of track for all Class 4 and 5 track;

- $\quad 0.09$ service failure per year per mile of track for all Class 3, 4, and 5 track that carries regularly-scheduled passenger trains or is a hazardous materials route;
- $\quad 0.08$ service failure per year per mile of track for all Class 3, 4, and 5 track that carries regularly-scheduled passenger trains and is a hazardous materials route.

Although rail inspection is currently not required for Track Classes 1 and 2, FRA does encourage the railroads to perform rail inspection on all track classes. Inspection requirements and intervals for higher classes of track (Track Classes 7 through 9) are currently under development.

\section{Human Error}

Current FRA regulations require the person assigned to operate rail defect detection equipment must be a qualified operator and have demonstrated proficiency in the rail flaw detection process (1). The meaning of "qualified operator" is clearly defined.

FRA requires that any provider of rail flaw detection services must have a documented training program to ensure that a rail flaw detection equipment operator is qualified to operate each of the various types of equipment currently utilized in the industry for which he or she is assigned, and that proper training is provided when new rail flaw detection technologies are introduced.

It is the responsibility of the railroad to reasonably ensure that any operator of rail flaw detection equipment over its track is qualified to conduct a proper inspection.

However, it is the responsibility of the qualified operator to conduct a valid search for internal rail flaws, determine that the equipment is functioning properly at all times, properly interpret the test results, and understand test equipment limitations. Rail inspection is subjective, and operator misinterpretation of test data, even though the equipment is functioning properly, does occasionally result in broken rails in revenue service.

\section{Delayed Repair}

FRA recently promulgated regulations which allow the railroads up to a four-hour period in which to verify that certain suspected defects exist in a rail section. This four-hour, deferred verification period applies only to suspected defects that may require less restrictive remedial action as described in the Track Safety Standards remedial action table (1).

The four-hour timeframe provides the railroad the flexibility to allow the rail flaw detector car to continue testing in a non-stop mode, without requiring verification of less serious, suspected defects. This flexibility also helps to avoid the need to operate the detector car in a non-test, "run light" mode over a possibly severe defective rail condition that could cause a derailment. It improves rail flaw detector car utilization, increases the opportunity to detect more serious defects, and ensures that rail inspection plans are completed. Recent developments within the industry have resulted in a more flexible approach to flaw detection by utilizing a continuous test and delayed verification approach. This process 
extends the verification time for less critical defects to 72 hours and better utilizes track maintenance resources and access to track time.

Once a rail defect is detected and verified, repair may be delayed due to lack of resources (e.g., the track welding gang is making repairs elsewhere) or lack of track access.

\section{Machine Errors}

Nondestructive test systems are designed to perform optimally on a perfect test specimen. In practice, much of the rail in the heavy haul freight industry is affected by wheel-rail contact stresses that cause plastic deformation of the rail. Subsurface cracks can grow at a shallow angle to the rail surface. These cracks can reflect the ultrasonic pulses from conventional rail inspection systems and hide defects in the head of the rail or not allow an adequate reflection to correctly categorize or estimate the size of a defect.

As a result, even the most experienced operator can potentially misclassify or improperly size a rail defect. Thus, it is important that rail defect detection technology continues to improve. Current research efforts include the use of ultrasonic guided waves to better characterize internal rail defects (8).

\section{Rail Surface Damage}

Rolling contact fatigue and any other type of rail surface damage can be an obstacle to detecting underlying rail defects. If the operator has any doubt or uncertainty in the integrity of the test process due to rail surface conditions, he or she has the option to record an invalid test and report the location to the railroad.

FRA's current rail inspection regulation states that when rail cannot be tested due to poor surface condition it must be reinspected before the next regulated inspection is due or the rail should be replaced (1). For example, if a valid search for internal rail defects could not be performed on a section of track that requires inspection every 30 million gross tons (MGT), and the invalid inspection took place $10 \mathrm{MGT}$ after the previous valid inspection, then the regulation requires a further valid inspection to be performed within the next $20 \mathrm{MGT}$.

\section{Undetectable Defect Type}

Ultrasound is the technology most frequently used by railroads to detect rail defects. In theory, ultrasonic waves are transmitted into locations in the rail where defects are most likely to be found and the echoes are studied for irregularities. The major characteristic that distinguishes different types of defect types is the defect's plane of propagation. To achieve reflection, the search beam must meet the defect plane at about 90 degrees. Although many advances have been made in rail defect detection, certain types of rail defects cannot be reliably detected. One example is a defect in the foot or the base of the rail, unless it is located directly under the web. Other types of defects that are not reliably detectable include: engine burn fracture, crushed head, and rail end weld fracture (9).

\section{Machine Stopped Due to Defects}

Current regulations require rail defects reported by the inspection car to be verified within a certain time period (1). In practice, this usually means a track gang follows the inspection car to perform manual verifications. An unintended consequence of the regulation may be that the inspection car is stopped when there are enough defects found to keep the track gang busy for the rest of its shift.

In 2009 FRA initiated through its waiver process a continuous test program that essentially allows the railroads to operate rail inspection cars in a non-stop mode and analyze the test data after collection. This delays the allowable verification within an extended timeframe. The process has shown excellent results in improving detector car utilization, track maintenance resource management, and reducing rail failure.

Continuous testing is less disruptive to revenue service operations. It enables inspection to be done more frequently, and it reduces the cost-per-mile of rail maintenance. Five U.S. Class I railroads currently perform the process.

\section{RECENT BROKEN RAIL DERAILMENTS}

The following discussions of recent accidents caused by broken rails illustrate the fault tree in Figure 1.

\section{Columbus, OH July 11, 2012}

The National Transportation Safety Board (NTSB) determined that the probable cause of the accident at Columbus, Ohio on July 11, 2012 was a broken rail that exhibited evidence of rolling contact fatigue (10). The derailment occurred in the body of a 9.5 degree curve with an average of 2 inches of superelevation. The track has a maximum authorized timetable speed of $25 \mathrm{mph}$ and is designated FRA Class 2 track. It is not a passenger route. It carries an annual gross tonnage of 37.7 MGT.

According to FRA regulations, this track is not required to be inspected for internal rail defects. However, such inspections were being conducted, with the most recent being on April 5, 2012; 97 days before the accident. That inspection found three defects that were corrected on the same day.

During the NTSB's reconstruction of the rail recovered after the derailment, investigators identified 24 oxidized internal cracks that fractured during the derailment. The running surface of the rail pieces showed evidence of flaking and severe rolling contact fatigue cracks.

The faults in Figure 1 that relate to this accident are "Rail Surface Damage" and "Worn Rail" (see Figure 2). The rail surface damage prevented the critical defects from being detected by ultrasonic test equipment. The loss of rail crosssection caused high rail stresses that, combined with the critical defects, led to the broken rail. 


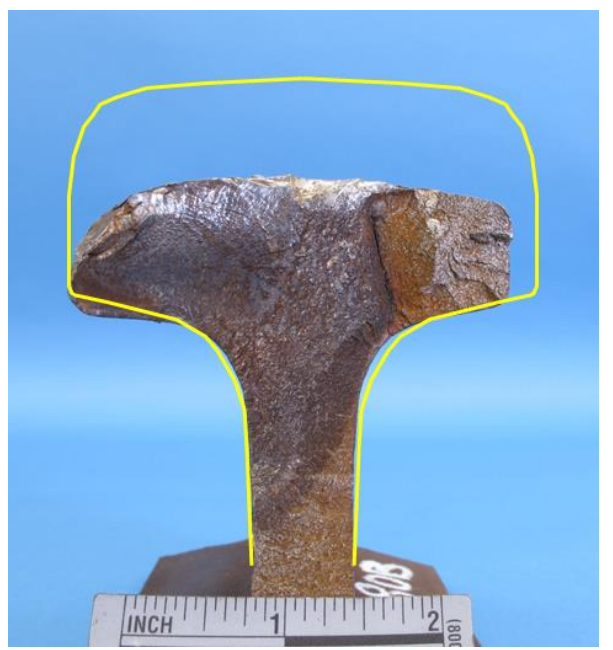

Figure 2. Worn Rail at Columbus (10)

The NTSB found rail surface damage and worn rail were also the probable faults that caused the accidents at Ellicott City, Maryland on August 20, 2012 (11) and at New Brighton, Pennsylvania on October 20, 2006 (12). NTSB recommendations from these accidents led to the formation of the Rail Failure Working Group of the Rail Safety Advisory Committee. This group developed the Rail Failure Prevention Program guidance document, which was distributed to the industry on July 25, 2014 (13). This document makes recommendations to the industry; to-date it has not resulted in any changes to regulations.

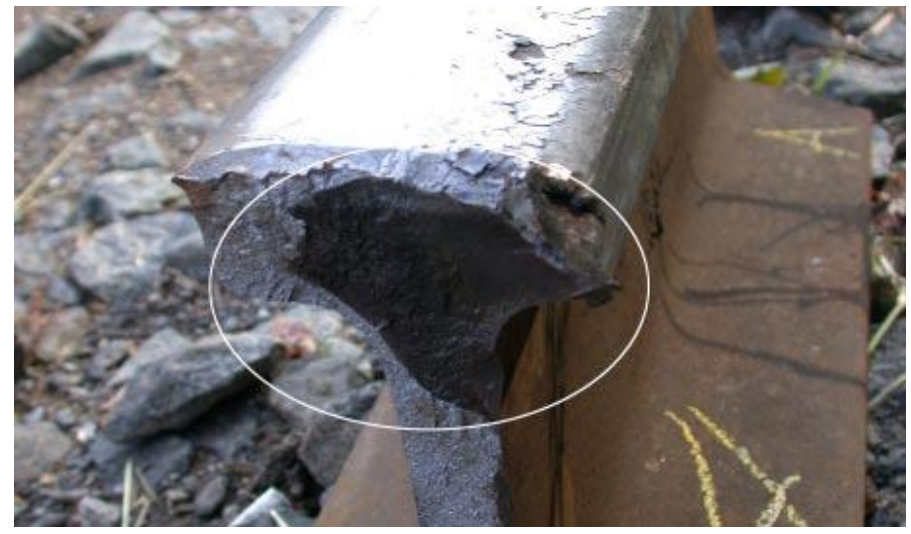

Figure 3. Broken rail and rail surface damage at New Brighton (12)

\section{Nodaway, IA March 17, 2001}

The NTSB determined that the probable cause of the accident involving the California Zephyr at Nodaway, Iowa on March 17, 2001 was a broken rail from undetected defects (14). The rail that failed was a plug rail that likely had pre-existing internal defects.

The primary fault that caused this accident was failure to inspect the plug rail for internal defects before it was installed.
This allowed any existing defects to grow to critical size before the next scheduled inspection on the line. At the time of the accident, this was fault "Inspection Not Required" in Figure 1.

NTSB recommended that FRA introduce a rule to ensure plug rail is free from internal defects (14). Current regulations do require plug rail to be ultrasonically inspected before use (1).

\section{Painesville, OH October 10, 2007}

The NTSB determined that the probable cause of the accident involving tank cars carrying ethanol at Painesville, Ohio on October 10, 2007 was a broken rail due to installation of the wrong type of joint bar (15). This is fault "Bad Rail Joint" in Figure 1. It likely led to high rail stress causing the joint to fail from the bolt holes as shown in Figure 4.

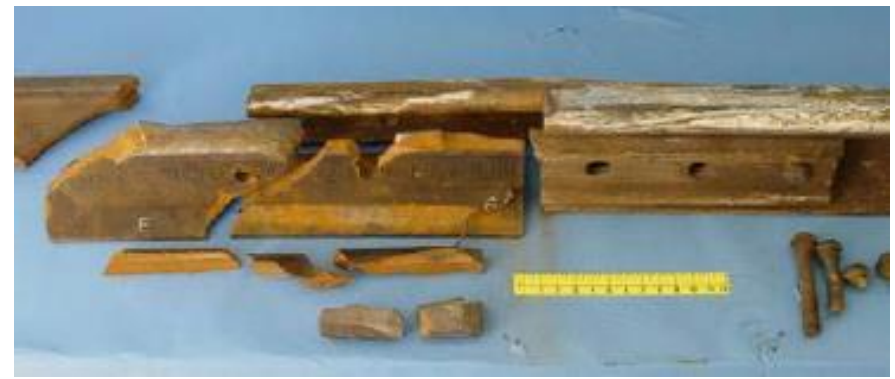

Figure 4. Reassembled Rail Joint from Painesville (16)

Previously, NTSB had found poor inspection and maintenance of joint bars to be the causes of the derailment at Minot, North Dakota on January 18, 2002 (16).

\section{Lynchburg, VA April 30, 2014}

On April 30, 2014 several tank cars carrying crude oil derailed near downtown Lynchburg, Virginia and caught fire, with some falling into the James River.

The probable cause of the derailment was rail failure from multiple detail fracture type defects. FRA's investigation determined that within the confirmed area of the derailment there was one detail fracture failure which was temporarily repaired in track. Adjacent to this failure, FRA also found a previously detected detail fracture that was left unprotected. This defect was identified during detector car operation on April 29, 2014, one day prior to the accident.

During the course of the accident investigation a third detail fracture failure was identified. This defect was below minimum detection size of $5 \%$ cross-sectional area of the rail head and was not identified by the detector car due to the detection limitations of current technology. The suspected cause of the derailment was the complete failure of the April 29, 2014 classified detail fracture and the adjacent undetected detail fracture.

The probable fault that led to this derailment was "Incorrect Remedial Action" in Figure 1. A rail defect of critical size was detected but not repaired as required by regulation. 


\section{Casselton, ND November 13, 2014}

On November 13, 2014 a freight train derailed into the path of an empty crude oil train on the adjacent track near the town of Casselton, North Dakota. As a result of the collision, 18 cars from the freight train derailed, and 11 empty tank cars derailed from the crude oil train.

FRA preliminary investigation results determined that the primary cause of the derailment was a broken rail from the presence of a detail fracture type defect. It was also determined that an additional detail fracture failure occurred adjacent to this primary defect as a result of the accident.

The defects were suspected to be of a detectable size at time of failure. The rail specimen showed the presence of gage side oriented rail shelling and head checking (see Figure 5). It was assumed that the rail surface condition influenced the equipment detection capabilities at time of test, and the defects were not identified by the test system. The primary fault that caused this accident was assumed to be technology limitations, and failure for the inspection equipment to identify the internal rail flaws.

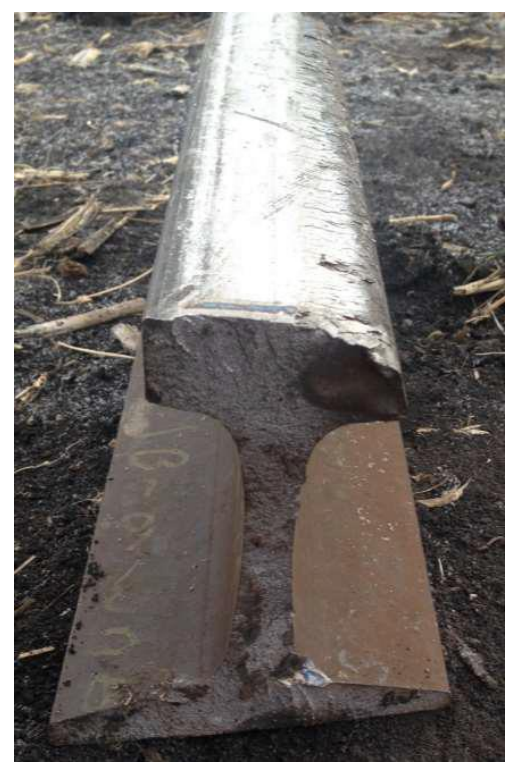

Figure 5. Rail surface damage and detail fracture at Casselton, ND

The probable fault that led to this derailment was "Rail Surface Damage" in Figure 1. A rail defect of critical size could not be detected due to the ultrasonic inspection being unable to penetrate the shelling and head checking on the surface of the rail.

\section{Mount Carbon, West Virginia February 16, 2015}

On February 16, 2015 an eastbound train transporting crude oil derailed west of Mount Carbon, West Virginia. A total of 27 tank cars derailed in the incident. Two tank cars were punctured, released crude oil, ignited, and caught fire. The fire spread quickly, resulting in a pool fire that eventually led to thermal tears in 13 additional derailed tank cars. Ultimately, 24 of the 27 derailed tank cars sustained damage in the incident and resulting fire.

FRA announced the cause of the derailment to be a broken rail, resulting from a vertical split head rail defect. The defect that eventually resulted in the derailment was missed by the railroad, and its defect detection services contractor on two separate inspections in the months leading up to the accident. During a December 17, 2014 test, the test equipment recorded indications of a rail flaw at what would become the point of derailment (see Figure 6). A subsequent test, on January 12, 2015 , noted a similar but more significant rail flaw indication at the same location. Despite indications of potential flaws, the operator failed to conduct a ground visual examination or hand tests to confirm the flaws as required by FRA regulations.

The probable fault that led to this derailment was "Human Error" in Figure 1. FRA published a safety advisory in November 2015 to address this issue (17).

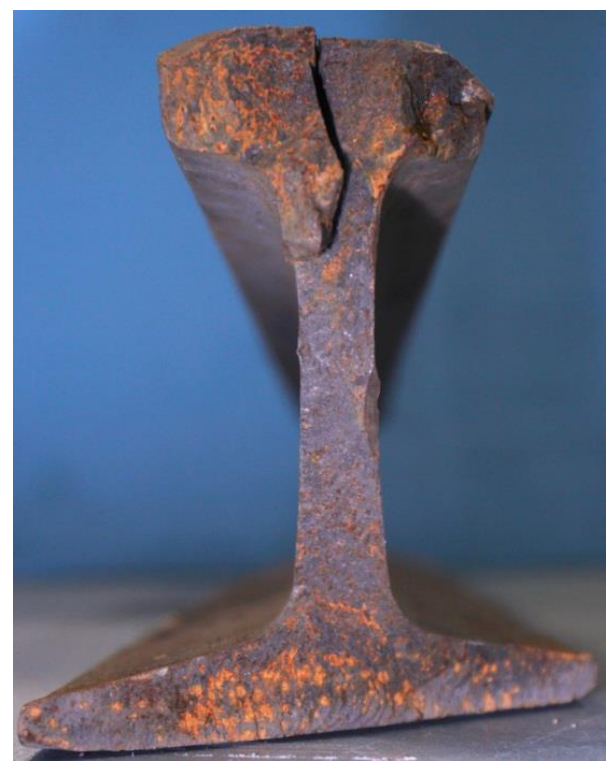

Figure 6. Vertical Split Head from the rail at Mount Carbon, WV

\section{New York, NY May 8, 2011}

On May 8, 2011 an eastbound Amtrak train experienced an undesired emergency application of the train air brakes and derailed five passenger cars on a mainline track in a tunnel under New York City. The probable cause of the derailment was determined to be broken rail from crack that originated in the rail base. The crack progressed upward into the head and web area, and propagated several feet before dislodging a teninch portion of the rail head. The rail had been inspected for internal rail defects 63 days prior to the train accident. Figure 7 shows the accident rail which contains a base defect with a crescent, thumbnail, or semi-elliptical shape. This type of rail 
base defect is more commonly found in tunnels where corrosion exacerbates the formation and growth of such defects. It illustrates the "Undetectable Defect Type" fault in Figure 1.

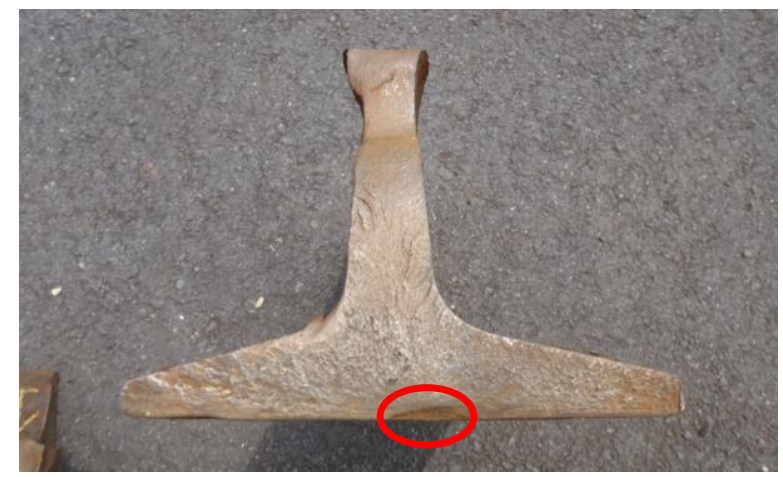

Figure 7. Rail Base Defect at New York

\section{CONCLUSIONS}

Broken rails in revenue service are caused by critical rail defects being present or high rail stresses, or a combination of both. The FRA and the industry have developed regulations and procedures to avoid both these faults, but recent accidents caused by broken rails show that more needs to be done.

AREMA gives guidance on appropriate rail sections for different types of revenue service to ensure normal rail bending stresses are acceptable. Bending stresses increase as rail wears, which can accelerate the growth of internal defects. This is one reason why railroads set limits on allowable head and side wear. Establishing a common set of limits for the industry seems to be a reasonable goal. Setting maximum allowable safety limits for rail wear would give the industry clear guidance to follow.

Bending stresses also increase when the rail is poorly supported by the ties, fasteners, ballast and subgrade. FRA regulations on ballast and subgrade support tend to be subjective. Methods for quantifying support conditions would allow more objectivity.

Thermal stresses in rails are controlled by adjusting the rail's neutral temperature. Each railroad establishes its own plan for managing rail neutral temperature depending on the geographic and climatic conditions in which it operates. Better methods for monitoring rail neutral temperature would help avoid high tensile stresses and rail breaks in cold temperatures.

Now that modern rail manufacturing processes produce high quality products relatively free from imperfections such as voids and inclusions, rail surface damage has emerged as a principal cause of broken rails in service. Research and development of inspection methods to see under the damaged surface of the rail should continue. The Government and the industry should combine their expertise to bring suitable products to market quickly.

Research should also continue into methods for detection of rail defects that are difficult or impossible to find with current technology. Examples include defects in the base of the rail, away from the centerline or those which exist beneath rail surface damage.

Human error is a principal cause of railroad accidents, and broken rail derailments are no exception. One remarkable observation from the fault tree in Figure 1 is that all faults represent single points of failure. Only one thing needs to go wrong before the broken rail hazard arises. This is most concerning when it comes to human error. No matter how good the technology, an error of judgement or a lack of expertise can lead to an accident. Thus, improvements to training, humanmachine interfaces, operator awareness and safety culture should be pursued.

Broken rails in revenue service can be eliminated if defects are detected and treated before they become critical and rail stresses are managed properly. Much progress has been made in recent decades in addressing these issues. The remaining challenges are known, and can be addressed through tighter regulations and improved industry practices.

\section{ACKNOWLEDGMENTS}

The work reported here was conducted by the Federal Railroad Administration. This document is disseminated under the sponsorship of the Department of Transportation in the interest of information exchange. The United States Government assumes no liability for its contents or use thereof. Any opinions, findings and conclusions, or recommendations expressed in this material do not necessarily reflect the views or policies of the United States Government, nor does mention of trade names, commercial products, or organizations imply endorsement by the United States Government.

\section{REFERENCES}

1. 49 CFR Part 213, Track Safety Standards, US Department of Transportation, Federal Railroad Administration.

2. American Railway Engineering and Maintenance-of-Way Association, Manual for Railway Engineering (2015).

3. Jeong, D.Y., Tang, Y.H., and Orringer, O., "Estimation of Rail Wear Limits Based on Rail Strength Investigations," DOT/FRA/ORD-98/07, December 1998. https://www.fra.dot.gov/eLib/details/L04326

4. Lyons, M.L., Jeong, D.Y., and Gordon, J.E., "Fracture mechanics approach to estimate rail wear limits," Proceedings of the 2009 ASME Rail Transportation Fall Technical Conference, RTDF2009-18035, October 2009 http://ntl.bts.gov/lib/35000/35200/35228/rtdf200918035.pdf.

5. Association of American Railroads, "Field Manual of the AAR Interchange Rules,” July 2015.

6. FRA, Safety Advisory 2015-01, "Mechanical Inspections and Wheel Impact Load Detector Standards for Trains Transporting Large Amounts of Class 3 Flammable Liquids," July, 2015. https://www.fra.dot.gov/eLib/details/L16322 
7. Orringer, O., "Control of Rail Integrity by Self-Adaptive Scheduling of Rail Tests", DOT/FRA/ORD-90/05, June 1990 https://www.fra.dot.gov/eLib/details/L16663.

8. Lanza di Scalea, et al. "Research and Development of Ultrasonic Tomography Technology for Three-

Dimensional Imaging of Internal Rail Flaws: Modeling and Simulation”, DOT/FRA/ORD-13/20, April 2013

https://www.fra.dot.gov/eLib/details/L04509.

9. Zarembski, A.M., and Palese, J.W., "Characterization of Broken Rail Risk for Freight and Passenger Railway Operations," AREMA 2005 Annual Conference, Chicago, IL, September 25-28, 2005.

https://www.arema.org/files/library/2005_Conference_Proc eedings/00008.pdf.

10. National Transportation Safety Board Railroad Accident Brief for Columbus, OH, July 12, 2012

http://www.ntsb.gov/investigations/AccidentReports/Repor ts/RAB1408.pdf.

11. National Transportation Safety Board Railroad Accident Brief for Ellicott City, MD August 20, 2012

http://www.ntsb.gov/investigations/AccidentReports/Repor ts/RAB1407.pdf.

12. National Transportation Safety Board, "Derailment of Norfolk Southern Railway Company Train 68QB119 with Release of Hazardous Materials and Fire New Brighton, Pennsylvania October 20, 2006," NTSB/RAR-09/02, PB2008-916302, May 2008
http://www.ntsb.gov/investigations/AccidentReports/Repor ts/RAR0802.pdf.

13. Rail Safety Advisory Committee (RSAC) Rail Failure Working Group, "Rail Failure Consensus Guidance Recommendations," July 2013

https://rsac.fra.dot.gov/meetings/RSAC\%20Rail\%20Failure \%20Consensus\%20Reccomendation.pdf.

14. National Transportation Safety Board Railroad Accident Brief for Nodaway, IA March 17, 2001

http://www.ntsb.gov/investigations/AccidentReports/Repor ts/RAB0201.pdf.

15. National Transportation Safety Board Railroad Accident Brief for Painesville, OH October 10, 2007 http://www.ntsb.gov/investigations/AccidentReports/Repor ts/RAB0902.pdf.

16. National Transportation Safety Board, "Derailment of Canadian Pacific Railway Freight Train 292-16 and Subsequent Release of Anhydrous Ammonia Near Minot, North Dakota January 18, 2002," NTSB/RAR-04/01, PB2004-916301, March 2004

http://www.ntsb.gov/investigations/AccidentReports/Repor ts/RAR0401.pdf.

17. FRA Safety Advisory 2015-05, “Addressing Rail Head Surface Conditions Identified during the Internal Rail Inspection Process," November 2015, https://www.fra.dot.gov/eLib/details/L17201. 